\title{
RADAR AND SEISMIC ICE-THICKNESS MEASUREMENTS COMPARED ON SUB-POLAR GLACIERS IN SVALBARD
}

\section{(Abstract)}

by

D.J. Drewry

(Scott Polar Research Institute, University of Cambridge, Cambridge CB2 1ER, U.K.)

\begin{abstract}
A comparison has been made of 46 radar-determined ice thicknesses and those resulting from seismic sounding on Bakaninbreen, Skobreen, and Paulabreen in central Spitsbergen. Significant differences were recorded between the two techniques, with $50 \%$ of the comparisons exceeding $15 \mathrm{~m}$. Systematic differences between the three glaciers were also observed: on Paulabreen the seismic ice depths are consistently deeper than those determined by radio echosounding, whilst the opposite is true on Skobreen.

Instrumental errors from the radar (SPRI $60 \mathrm{MHz}$ unit) and seismic equipment (ABEM Terraloc) are considered small or insignificant. Factors affecting the respective propagation velocities may be responsible for differences in mean thickness particularly in the case of seismic waves, although the changes are obtained from the first returns. One hypothesis to explain the differences on Paulabreen and to a lesser degree on Bakaninbreen, is that these glaciers are underlain by a seismic low-velocity layer due to the presence of moraine or till. Unfortunately, equipment problems in the field prevented the digital logging of the seismic data and the analogue records are not of sufficient quality for detailed analyses to reveal the possible presence of a till horizon and its seismic velocities. However,
\end{abstract}

observations at the snout of Paulabreen show considerable thicknesses of basal till. With a "P"-wave velocity in such a layer close to or less than that of ice acoustic returns would possibly come from the till-bedrock interface, whereas radar returns would be from the region of the ice-till boundary.

For the seismic ice depths that are shallower than the radar soundings on Skobreen an alternative explanation is required. The valley occupied by the glacier is considerably narrower than in the case of the other two glaciers. According to one detailed radio echo-sounding cross-profile, the line of the combined seismic and radar sounding was displaced to one side of the centre and deepest part of the glacier. This would result in early seismic returns from the nearest facets of the valley side rather than the subjacent bed. The radio waves, however, undergo a focussing effect in the ice, giving rise to a considerably smaller footprint. The difference in slant length between the general area of the bed viewed by the radar and that returning seismic energy is approximately $+15-20 \mathrm{~m}$ at the location of the cross-profile. This value is of the order of the differences between the two systems and could therefore account for the observed disparity here and at the other locations.

\section{ACOUSTIC EMISSION METHODS APPLIED TO AVALANCHE-FORMATION STUDIES}

\author{
(Abstract) \\ by
}

V.P. Epifanov

(U.S.S.R. Academy of Sciences, Institute of Problems of Mechanics, Moscow, U.S.S.R.)

and

V.P. Kuz'menko

(U.S.S.R. Goskomgidromet, Central Asian Regional Research Institute, Tashkent, U.S.S.R.).)

\begin{abstract}
The relationship between the intensity of snow acoustic emission impulses and snow-cover stability is revealed by measuring the physical and mechanical properties of the snow cover in the starting zones of avalanches. This relationship is fundamental to the remote identification of an avalanche-hazard period.
\end{abstract}

In order to estimate the mechanical properties of a snow layer, a method of applying a rigid penetrometer equipped with a piezoelectric accelerometer is used. The viscosity coefficients of snow under destruction and the specific energy of destruction are determined. The overall effect of the different elements of destruction is assessed using both structural investigations and acoustic methods (acoustic emissions). 